E3S Web of Conferences 1, 02001 (2013)

DOI: $10.1051 / \mathrm{e} 3$ sconf/20130102001

(C) Owned by the authors, published by EDP Sciences, 2013

\title{
Bioavailability of Metals in Contaminated Sediments
}

\author{
M. H. Paller $^{1}$ and A. S. Knox ${ }^{1}$ \\ ${ }^{1}$ Savannah River National Laboratory, Aiken, SC 29808, USA, Phone: 803725 5250, Fax: 8037257673 , \\ michael.paller@srnl.doe.gov
}

\begin{abstract}
Bioavailability controls the transfer of metals from sediments to ecological receptors and humans. It can rarely be predicted from total metal concentrations because it is affected by metal geochemistry in sediments as well as the biochemistry, physiology, and behavior of benthic organisms. There is no single approach for including bioavailability in risk assessments because of variability in site specific conditions and the difficulty of validating methods. Acid-volatile sulfide and simultaneously extracted metals are useful in predicting bioavailability in anoxic sediments containing sulfides that react to form insoluble metal complexes. This method can be improved by adjusting for organic carbon and other ligands that also bind free metals. Site-specific desorption $\mathrm{K}_{\mathrm{d}}$ values calculated by sequential extraction methods can be useful in predicting bioavailable metal fractions in oxic and anoxic sediments. A modified desorption distribution coefficient $\left(\mathrm{K}_{\mathrm{dg}}\right)$ can be calculated by extraction with the digestive gut fluids of sediment feeding organisms to account for the effects of ingestion on metal release from sediments. Recently developed in situ measurement technologies can accumulate dissolved metals in a controlled fashion that may correspond with bioavailable metal fractions in sediment. Successful evaluation of bioavailability requires the selection of methods suitable for the organisms and sediment environments under consideration. A weight-of-evidence approach that incorporates multiple lines of evidence can help address uncertainties and increase the likelihood of incorporating bioavailability into remedial decisions.
\end{abstract}

Key words: bioavailability, sediments, geochemistry, benthos, metals, risk assessment

\section{Introduction}

Contaminated sediments pose a potential risk to the aquatic environment and human health because they release recalcitrant chemicals that can harm organisms and enter aquatic food chains that lead to humans. However, only the contaminant fraction that is available for biological uptake has the potential to cause human health or ecological risks. Bioavailability can be defined as the degree to which chemicals present in the sediment/soil are absorbed or metabolized by human or ecological receptors or are available for interactions with biological systems (ISO, 2005). It depends on the specific target organism, contaminant, and sediment environment and includes exposure time, transfer of contaminants from sediment to organisms, their accumulation in the organisms, and the subsequent effects of the contaminants. Technical uncertainties have precluded the consensus among scientists, regulators, and public that is needed to fully integrate bioavailability into risk assessment and regulatory decisions. This can lead to cleanup goals that default to conservative screening levels and unnecessarily expensive and intrusive remedial actions.

\section{Geochemical factors affecting bioavailability}

The total concentrations of metals cannot predict environmental impacts because the speciation of metals in sediments influences metal bioavailability. In fact, metal bioaccumulation is rarely related to total metal concentrations. Bioavailability is a dynamic process that can be described by three steps: 1) availability of the contaminant in the sediment (i.e., environmental availability); 2) uptake of the contaminant by the organism (i.e., environmental bioavailability); and 3) availability in the organism, accumulation, and effect of the contaminant (i.e., toxicological bioavailability) (Peijnenburg et al., 1997).

The release of contaminants from the sediment matrix is a first step in determining bioavailability. It depends on 
local environmental parameters, particularly $\mathrm{pH}$, redox oxidation potential, dissolved organic carbon, inorganic complexes, organic complexes, and sediment particle size. Anoxic sediments contain iron monosulfides that react with metal cations to form insoluble metal sulfides. For such sediments, acid-volatile sulfide (AVS, the sulfides removed from sediment by cold acid extraction) is an important factor affecting the bioavailability of divalent metals with a high affinity for sulfide (Di Toro et al, 1990). The ability of AVS to predict bioavailability and toxicity can be improved by adjusting for organic carbon and other solid-phase and dissolved-phase ligands present in sediments that also bind free metals and reduce their bioavailability (USEPA equilibrium partitioning sediment benchmarks, USEPA 2001). Few studies have considered the redistribution of released trace metals bound to AVS from anoxic sediments when the original anoxic conditions have been changed.

Metals in oxic sediments are often sorbed to iron and manganese oxides, clay particles, and organic carbon sources. These complexes can be represented by different operationally defined geochemical phases such as carbonates, total organic carbon (TOC), and Fe-Mn oxides that have contrasting influences on metal bioavailability. Sediments can be sequentially extracted using chemicals of decreasing $\mathrm{pH}$ and increasing oxidizing strength to remove these geochemical phases and potentially relate them to the bioavailable metal fraction in the total contaminant pool. For example, the recalcitrant fraction, which consists of metals contained within the crystal structure of minerals, is typically unavailable to biota (Knox et al., 2006).

\section{Biological factors affecting bioavailability}

In addition to metal geochemistry, the biochemistry, physiology, and feeding behavior of benthic organisms can strongly influence metal bioavailability. Fan and Wang (2001) emphasized that geochemical factors alone were not responsible for the bioavailability of sediment bound metals to marine mussels and clams. Correlations have been found between metal uptake and the metal fractions extracted by gut juice (Mayer et al., 1996) indicating the importance of digestive system physiology in determining metal uptake. Feeding behaviors are important because they affect the exposure scenarios of benthic organisms. Deposit feeding infauna, such as some annelid worms, can accumulate toxicants through diet and direct adsorption to the body wall. Filter feeding infauna, such as some clams, reside in direct contact with contaminated sediments but obtain nutrition from the overlying water. Still other exposure scenarios are experienced by motile epifauna (e.g., decapods) that scavenge or browse at the sediment surface and by nekton (e.g., fish) that live in the water column but feed on sediment dwelling organisms.

Understanding differences in exposure requires detailed knowledge of organismal behavior. For example, estuarine amphipods such as Eohaustorius estuaries and Leptocheirus plumulosus, and polychaetes such as Neanthes arenaceodentata ingest sediment indicating they are exposed to metals through both dissolved and dietary pathways. However, the amphipods are free burrowers while the polychaete is a tube builder, suggesting the route of uptake likely differs between these organisms. Determining the exposure scenarios experienced by benthic organisms is complicated by spatial changes in sediment biogeochemistry, especially changes in redox state associated with sediment depth. For example, epibenthic or shallowly burrowing amphipods (e.g., Hyalella azteca) that may reside in oxic sediments would be expected to experience significantly different exposure scenarios than deeper burrowing polycheate worms (e.g., taxa in Opheliidae).

Physiological factors such as ingestion rates, growth rates, and lipid levels can also affect bioaccumulation. These factors are likely to be species specific and may also vary within species due to food quality, environmental conditions, and life history characteristics making it difficult to predict body burdens. Given these variations, it may be beneficial to use multiple species and endpoints when assessing bioavailability because different organisms have different propensities to regulate, compartmentalize, and detoxify metals.

\section{Bioavailability measurement methods}

\section{Acid-volatile sulfide (AVS) and simultaneously extracted metals (SEM)}

AVS present in anaerobic sediments is mostly bound to $\mathrm{Fe}$ as solid iron monosulfide (FeS) (Hansen et al., 1996). If divalent metals such as $\mathrm{Cd}, \mathrm{Cu}, \mathrm{Cr}, \mathrm{Pb}, \mathrm{Ni}$, or $\mathrm{Zn}$ are present, however, the iron in $\mathrm{FeS}$ is displaced and one of these metals binds to AVS removing it from the interstitial water (Di Toro et al., 1990). The concentration of bioavailable metals, or metals that are unbound and available to organisms, can be estimated from the ratio of simultaneously extracted metal (SEM) to the AVS concentration. An SEM to AVS ratio greater than one indicates that excess metals are present in the sediment relative to AVS. These unbound metals have the potential to be significantly more bioavailable than those bound to sulfides. However, feeding behavior and dietary uptake rather than exposure to interstitial pore water may control metal bioaccumulation in some cases. Lee at al. (2000) reported that metal concentrations in animal tissue correlated with metal concentrations extracted from sediments but not with metal concentrations in pore water across a range of reactive sulfide concentrations. AVS can be extracted from sediment samples with cold one-molar hydrochloric acid. Additionally, this method can be enhanced by normalizing the SEM/AVS ratio to organic carbon and other ligands.

\section{Site-specific desorption $K_{d}$ values calculated by sequential} extraction 
The site-specific desorption $K_{d}$ of metals in sediments identifies the metal fraction that is readily available for entry into interstitial water or surface water; i.e., the potentially bioavailable fraction (PBF) (Knox et al., 2006). It can be operationally defined by selective extractions, with the intent of providing a conservative (high) estimate of the amount of a contaminant that may be released from the sediment. The contaminant pool not associated with the PBF can only be extracted from sediments with extremely strong acids and reductants that dissolve minerals. The magnitude of the PBF depends on the sorption mechanism of the metal to the sediment.

The $\mathrm{K}_{\mathrm{d}}$ construct assumes that sorption is linear and reversible. "Linear" indicates that the aqueous contaminant concentration does not influence sorption. "Reversible" indicates that the rate of sorption is equal to the rate of desorption. The numerator of a $\mathrm{K}_{\mathrm{d}}, \mathrm{C}_{\text {solid, should reflect }}$ only the reversibly sorbed contaminant concentration to avoid overestimating true $K_{d}$ values.

There is no universally agreed upon metal fraction or extraction technique that can be used to identify bioavailable metal fractions in oxic sediments. Tessier (1979) and Hall (1996) extracted the following fractions: i) exchangeable, ii) carbonate, iii) amorphous $\mathrm{Fe}$ and $\mathrm{Mn}$ oxides, iv) crystalline $\mathrm{Fe}$ and $\mathrm{Mn}$ oxides, v) organic, vi) sulfides, and vii) residual. For sediments with high content of organic matter, a soluble organic fraction can be included as the first step followed by exchangeable, amorphous oxide, crystalline oxide, and organic fractions. Results can be used to calculate desorption $\mathrm{K}_{\mathrm{d}}$ values for oxic environments as follows:

$$
\text { Desorption } K_{d}=\frac{C_{E x c h}+C_{A m o r p h F e}+C_{O r g}}{C_{a q}}
$$

Where:

$C_{E x c h}=$ metal concentration in exchangeable and/or carbonate sequential extraction fractions $(\mu \mathrm{g} / \mathrm{g})$,

$C_{\text {AmorphFe }}=$ metal concentration in the amorphous Fe-oxide sequential extraction fraction $(\mu \mathrm{g} / \mathrm{g})$,

$C_{\text {Org }}=$ metal concentration in the organic sequential extraction fraction $(\mu \mathrm{g} / \mathrm{g})$, and

$C_{a q}=$ metal pore water concentration $(\mu \mathrm{g} / \mathrm{L})$.

$C_{a q}$ in this equation is typically derived from pore water extracted using conventional methods (e.g., peepers or centrifugation).

\section{Digestive gut fluid extractions - a modified desorption distribution coefficient $\left(K_{d g}\right)$}

A biomimetic approach can be used to determine the pool of bioavailable metals in sediment by extraction with the digestive gut fluids of sediment feeding organisms such as the peanut worm Sipunculus nudus or lugworm Arenicola marina. Extraction with digestive fluid of $A$. marina has been shown to be a good predictor of mercury bioaccumulation by the deposit feeding amphipod Leptocheirus plumulosus (Lawrence et al., 1999). Gut fluid extractions can be conducted on bulk sediment samples and on the residue from metal fractions produced by sequential extractions. This can determine the geochemical metal phase(s) that are likely to be physiologically mobilized in the digestive systems of sediment feeding invertebrates and facilitate linkage between geochemical and biomimetic methods of assessing bioavailability. The results from digestive fluid extractions can be used to calculate a modified desorption distribution coefficient $\left(\mathrm{K}_{\mathrm{dg}}\right)$ based only on fractions showing metal release by the gut.

\section{In situ measurement technologies}

Pore water chemistry measured directly (e.g., in poor water collected by sippers) can be used to estimate the bioavailable contaminant fraction in sediments, but recently developed in situ measurement technologies offer additional potential to integrate some of the biological and biogeochemical factors that control metal bioavailability. DGT probes can be used to accumulate dissolved metals in a controlled fashion that permits precise measurements of trace metals and other substances in sediment. DGT actively removes metals from water, pore water, and sediments, thus mimicking the effects of biota while providing quantitative measurement of the mean concentration of metals in pore water at the surface of the device (Davison and Zhang, 1994). DGT can theoretically measure labile species that correspond closely to bioavailable metal fractions in sediment and can measure vertical profiles of available contaminants. The latter can provide information on contaminant migration rates, identify microniche environments, and quantify fluxes of solutes within the sediment environment. Other surrogate sampling technologies include gel probe equilibrium samplers (Campbell et al. 2008) and acid volatile gel probes (Edenborn 2005).

\section{Validating bioavailability measurement methods}

The various geochemical and biological factors that potentially affect metal bioavailability combined with the availability of different techniques for measuring bioavailable metal fractions indicate a need to assess the relative capabilities of different bioavailability methods to accurately predict uptake. However, comparing methodological results with uptake under natural conditions is difficult because of the spatial heterogeneity typical of contaminant distribution, the relatively large territories of some organisms relative to the size of the contaminated area, temporal changes in contaminant levels due to sediment transport processes, temporal changes in sediment geochemistry, and ignorance concerning organism exposure scenarios.

Laboratory bioassays can directly measure sedimentspecific bioavailability to aquatic organisms while 
controlling confounding variables but may produce artificial results that lack congruence with real world conditions. Mesocosms are an alternative that represent a middle-ground between the laboratory and the field. They support simplified natural communities under conditions that permit the continuance of natural processes without losing replication and experimental control.

Mesocosm and laboratory studies can be corroborated through field deployments of organisms and bioavailability measurements in situ. In situ bioassays include realistic exposure scenarios, reduction of sampling related artifacts, integration of site-specific conditions, the ability to deploy and assess within days, and the ability to partition exposures of key compartments (e.g. reduced or oxidized sediments, sediment-water interface, water column).

\section{Conclusion}

Site specificity remains a significant problem when assessing bioavailability. It is unlikely that a single indicator of metal bioavailability will be suitable for all situations because of the physical and chemical heterogeneity of sediments combined with differences in the exposure scenarios experienced by different organisms as a result of variations in feeding behavior, depth of residence in the sediment column, physiology, and other factors. Successful evaluation of bioavailability will result from the selection of analytical methods that are suitable for the organisms and sediment environments under consideration. A weight-of-evidence approach may maximize the likelihood of incorporating bioavailability measurements into remedial decisions by helping to overcome skepticism by the regulatory community and public. Such an approach will incorporate multiple lines of evidence to address the technical uncertainty associated with individual methods. The Sediment Quality Triad is an example of a weight of evidence approach that incorporates comparisons of environmental contaminant concentrations to screening values, laboratory toxicity evaluations, and community analyses, although it does not, in its usual form, incorporate bioavailability measurements.

\section{References}

Campbell KM., Root R., O’Day PA., Hering J.G. A gel probe equilibrium sampler for measuring arsenic porewater profiles and sorption gradients in sediments: I. Laboratory Development. Environ. Sci. Technol. 2008; 42:497-503.

Davison W, Zhang H. In situ speciation measurements of trace components in natural waters using thinfilm gels. Nature 1994; 367:546-548.

Di Toro DM, Mahony JH, Hansen DJ, Scott KJ, Hicks MB, Mayr SM, Redmond M. Toxicity of cadmium in sediments: the role of acid volatile sulfides. Environ. Toxicol. Chem. 1990; 9:1487-1502.

Edenborn HM. Rapid detection of bioavailable heavy metals in sediment porewaters using acid-volatile sulfide gel probes. Environmental Geology 2005; 47:660-669.

Fan W, Wang W-X. Sediment geochemical controls on $\mathrm{Cd}, \mathrm{Cr}$, and $\mathrm{Zn}$ assimilation by the clam Ruditapes philippinarum. Environ. Toxicol. Chem. 2001; 20:2309-2317.

Hall GEM, Vaive JE, Beer R, Hoashi M. Selective leaches revisited, with emphasis on the amorphous $\mathrm{Fe}$ oxyhydroxide phase extraction. J. Geochem. Exploration 1996; 56:59-78.

Hansen DJ, Berry WJ, Mahony JD, Boothman WS. Predicting the toxicity of metal-contaminated field sediments using interstitial concentration of metals and acid-volatile normalizations. Environ. Toxicol. Chem. 1996; 15:2080-2094.

ISO. 11074: Soil-quality-Vocabulary. ISO, Geneva, Switzerland. 2005.

Knox AS, Paller MH, Nelson E, Specht W, Gladden J. Contaminant assessment and their distribution and stability in constructed wetland sediments, J. Environ. Qual. 2006; 35: 1948-1959.

Lawrence AL, McAloon KM, Mason R, Mayer M. Intestinal solubilization of particle-associated organic and inorganic mercury as a measure of bioavailability to benthic invertebrates. Environ. Sci. Technol. 1999; 33:1871-1876.

Lee B-G., Griscom SB, Lee J-S, Choi HJ, Koh C-H, Luoma $\mathrm{SN}$, Fischer NS. Influences of dietary uptake and reactive sulfides on metal bioavailability from aquatic sediments. Science 2000; 287: 282-284.

Mayer LM, Chen Z, Findlay RH, Fang J, Sampson S, Self RFL, Jumars PA, Quetel C, Donard OFX. Bioavailability of sedimentary contaminants subject to deposit-feeder digestion. Environ. Sci. Technol. 1996; 30:2641-2645.

Peijnenburg W, Posthuma L, Eijsackers H, Allen H. A conceptual framework for implementation of bioavailability of metals for environmental management purposes. Ecotoxicol. Environ. Saf. 1997; 37:163-172.

Tessier A, Campbell PGC, Bisson M. Sequential extraction procedure for the speciation of particulate trace metals. Anal. Chem. 1979; 51:844-850.

US EPA. The incidence and severity of sediment contamination in surface waters of the United States. National sediment survey: second edition. EPA/823/R01/01. (Draft). U.S. Environmental Protection Agency, Washington, D.C. 2001. 